\title{
BMJ Open Health programmes and services addressing the prevention and management of infectious diseases in people who inject drugs in Canada: a systematic integrative review
}

\author{
Katrina Bouzanis (D) , ${ }^{1}$ Siddharth Joshi, ${ }^{2}$ Cynthia Lokker, ${ }^{2}$ \\ Sureka Pavalagantharajah, ${ }^{3}$ Yun Qiu, ${ }^{4}$ Hargun Sidhu, ${ }^{3}$ Lawrence Mbuagbaw (D) ,2 \\ Majdi Qutob, ${ }^{5}$ Alia Henedi, ${ }^{6}$ Mitchell A H Levine, ${ }^{2}$ Robin Lennox, ${ }^{7}$ \\ Jean-Eric Tarride, ${ }^{2,8}$ Dale Kalina, ${ }^{9}$ Elizabeth Alvarez (1) ${ }^{2,10}$
}

To cite: Bouzanis K, Joshi S, Lokker C, et al. Health programmes and services addressing the prevention and management of infectious diseases in people who inject drugs in Canada: a systematic integrative review. BMJ Open 2021:11:e047511. doi:10.1136/ bmjopen-2020-047511

- Prepublication history and additional supplemental material for this paper are available online. To view these files, please visit the journal online (http://dx.doi.org/10.1136/ bmjopen-2020-047511).

Received 30 November 2020 Accepted 24 August 2021

Check for updates

(C) Author(s) (or their employer(s)) 2021. Re-use permitted under CC BY-NC. No commercial re-use. See rights and permissions. Published by BMJ.

For numbered affiliations see end of article.

Correspondence to

Katrina Bouzanis;

katrina.bouzanis@gmail.com

\section{ABSTRACT}

Objectives People who inject drugs (PWID) experience a high burden of injection drug use-related infectious disease and challenges in accessing adequate care. This study sought to identify programmes and services in Canada addressing the prevention and management of infectious disease in PWID.

Design This study employed a systematic integrative review methodology. Electronic databases (PubMed, CINAHL and Web of Science Core Collection) and relevant websites were searched for literature published between 2008 and 2019 (last search date was 6 June 2019). Eligible articles and documents were required to address injection or intravenous drug use and health programmes or services relating to the prevention or management of infectious diseases in Canada.

Results This study identified 1607 unique articles and 97 were included in this study. The health programmes and services identified included testing and management of HIV and hepatitis $\mathrm{C}$ virus $(\mathrm{n}=27)$, supervised injection facilities $(n=19)$, medication treatment for opioid use disorder $(n=12)$, integrated infectious disease and addiction programmes $(n=10)$, needle exchange programmes $(n=9)$, harm reduction strategies broadly $(n=6)$, mobile care initiatives $(n=5)$, peer-delivered services $(n=3)$, management of IDU-related bacterial infections $(\mathrm{n}=2)$ and others $(\mathrm{n}=4)$. Key implications for policy, practice and future research were identified based on the results of the included studies, which include addressing individual and systemic factors that impede care, furthering evaluation of programmes and the need to provide comprehensive care to PWID, involving medical care, social support and harm reduction.

Conclusions These results demonstrate the need for expanded services across a variety of settings and populations. Our study emphasises the importance of addressing social and structural factors that impede infectious disease care for PWID. Further research is needed to improve evaluation of health programmes and services and contextual factors surrounding accessing services or returning to care.

PROSPERO registration number CRD42020142947.

\section{STRENGTHS AND LIMITATIONS OF THIS STUDY}

$\Rightarrow$ A systematic integrative review allowed for the inclusion of empirical, non-empirical and grey literature and enabled a broad overview of health programmes and services available for people who inject drugs in Canada.

$\Rightarrow$ Article screening, data extraction and quality assessment were performed independently by two reviewers, improving reproducibility and limiting bias.

$\Rightarrow$ This review is limited to published literature, which may exclude programmes or services not published.

$\Rightarrow$ This review was limited to Canada, reducing the generalisability of these results; however, improving the specificity of policy and practice recommendations derived from these results.

\section{BACKGROUND}

Injection drug use (IDU) and intravenous drug use (IVDU) are major public health problems in Canada, with the number of people who inject drugs (PWID) increasing over the last decade. ${ }^{1}$ IDU is associated with adverse health and social outcomes including overdoses, poor access to medical care and social support, and spread of infectious disease. ${ }^{2}$ PWID are at increased risk for viral blood-borne infections, such as human immunodeficiency virus (HIV) and hepatitis $\mathrm{C}$ virus (HCV), bacterial infections, including endocarditis and skin and soft tissue infections, and fungal infections. According to the Public Health Agency of Canada (PHAC), $68 \%$ of PWID in Canada have been infected or are currently infected with $\mathrm{HCV}^{3}$ Additionally, PWID are 59 times more likely to contract HIV than people who do not use injection drugs. ${ }^{4}$ 
The high incidence of infectious disease among PWID and other adverse health outcomes have resulted in increased emphasis on harm reduction efforts. These include supervised injection facilities (SIFs) and needle exchange programmes (NEPs). The use of medication treatment as management for opioid use disorder has been associated with a reduction in IDU. ${ }^{5-7}$ These harm reduction efforts are well-established methods of preventing infectious disease in PWID. ${ }^{8-10}$ Additionally, guidelines are well established for the treatment of infectious diseases commonly associated with IDU, such as antiretroviral therapy (ART) for HIV or direct-acting antivirals for HCV. ${ }^{11-14}$

PWID may experience a range of healthcare trajectories, barriers to care and fragmentation between social and health systems, which impede infectious disease prevention or management. ${ }^{2}$ PWID are frequently hospitalised, have higher rates of patient-initiated or self- discharge and face system barriers that make it difficult to assess clinical outcomes. ${ }^{1516}$ The scope of healthcare services and programmes across Canada that aim to prevent and treat infectious diseases in PWID remains unclear. The purpose of this study is to describe literature available on health programmes and services in Canada relating to the prevention and management of infectious diseases in PWID, with the hope of informing policy, practice and future research. This study employed an integrative systematic review methodology, allowing for the inclusion of a variety of study designs, including experimental and non-experimental research. The diversity and broadness of studies included in this type of review is well suited to informing evidence-based policy and practices. ${ }^{17}$

\section{METHODS}

This research followed an integrative systematic review as outlined by Whittemore and Knafl ${ }^{17}$ and has been previously described elsewhere. ${ }^{18}$ An integrative systematic review may be used to gather diverse and broad evidence, allowing the inclusion of varying methodologies to understand the breadth of a health issue. ${ }^{18}$ This manuscript follows the Preferred Reporting Items for Systematic Reviews and Meta-Analyses (PRISMA) guidelines adapted for scoping reviews. ${ }^{19}$

\section{Literature search}

PubMed, CINAHL and Web of Science Core Collection electronic databases were searched for empirical literature between 2008 and 6 June 2019 (one additional year from that indicated in the published protocol paper ${ }^{18}$ to include studies from at least 10 years). Additionally, PHAC, the Canadian Institute for Substance Use Research and Canadian Centre on Substance Use and Addiction websites were searched. The search strategy included terms for infectious diseases (infecti*, endocarditis, hepatitis, HIV, AIDS, pneumonia, abscess, osteomyelitis, septicemia, tetanus), drug use (drug use*, drug abuse, drug misuse, injection drug, drug inject*, IDU, IVDU, PWID, intravenous, overdose, illicit) and geography (Canada, Alberta, British Columbia, BC, Manitoba, New Brunswick, Newfoundland Labrador, Nova Scotia, Ontario, Prince Edward Island, Quebec, Saskatchewan, Nunavut, Northwest Territories, Yukon). The full search strategy is described in online supplemental files 1 . References of included articles were hand-searched for additional relevant articles.

\section{Inclusion/exclusion}

For eligibility, articles and documents were required to address injection or intravenous drug use and health programmes or services relating to the prevention or management of infectious diseases in Canada. Articles or documents reporting drug efficacy trials, published prior to 2008, or not in English or French were excluded.

More than 55 articles (over 5\%) were reviewed for inclusion/exclusion by the entire data collection team to ensure consistency. Titles and abstracts were screened independently by two reviewers. Conflicts were resolved by consensus or a third reviewer when necessary. Fulltext screening for remaining articles was conducted by two independent reviewers with consensus or review by a third individual when necessary. A list of articles excluded at the full-text stage is available on request.

\section{Data extraction}

A data extraction form was used to collect the following: bibliographic data, type of research study and design, location, site of health programme or service (community, clinic, hospital, etc), infection(s) discussed, description of health programme or service, population of study within PWID, description of cohort (if part of a cohort study), purpose of study, outcomes measured, summary of findings, implications for policy, practice or research and gaps according to authors. Data extraction was performed by a primary data collector, followed by independent review by a secondary data collector.

\section{Data analysis and quality appraisal}

Data were organised in tables to categorise certain characteristics, such as the study design, types of health programmes or services, infectious diseases, locations and PWID subpopulations. Implications for policy and practice, and areas for future research were identified. There was too much diversity in study types and outcomes to conduct a meta-analysis; therefore, narrative descriptions are provided but an overall conclusion on efficacy of interventions could not be determined.

Quality appraisal was performed according to the Quality Assessment Tool for Studies with Diverse Designs (QATSDD). ${ }^{20}$ This tool was chosen due to its applicability to diverse study types, including quantitative and qualitative methodologies. The tool was validated by health service researchers, increasing the reliability of its use in this study. ${ }^{20}$ Each included empirical study was appraised by two reviewers, and a final score was determined by consensus. 


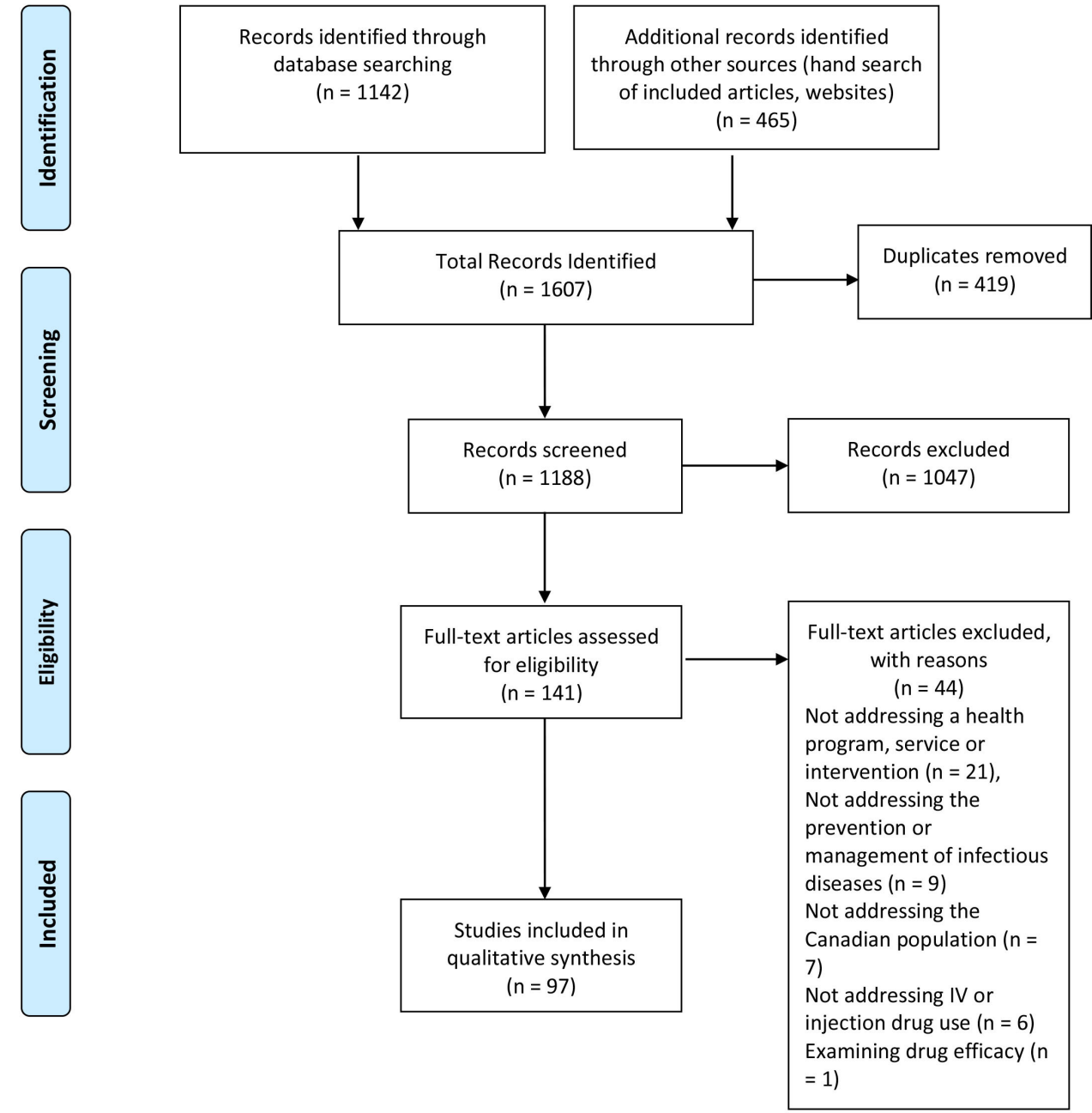

Figure 1 Flow chart demonstrating identification, screening and inclusion of studies (from Moher et al). ${ }^{121}$

\section{RESULTS}

\section{Characteristics of included studies}

We identified 1142 citations from the database searches and 465 citations from manually searching the references of included documents and other sources (figure 1). Of the 1607 citations identified, 419 duplicates were removed, leaving 1188 studies for potential inclusion. Articles were excluded through title and abstract screening (1047 documents) or full-text screening ( 44 documents). A total of 97 studies were included in the study for data extraction.

Empirical studies, non-empirical studies and grey literature were included, resulting in a variety of methodologies and study designs (table 1). Additionally, table 1 provides a breakdown of the infections discussed, jurisdiction of health programme or service and population within PWID discussed in included studies. QATSDD scores of empirical studies ranged from $31 \%-83.3 \%$. Study sizes ranged from 11 to 36077 participants.

\section{Health programmes and services}

Included studies were categorised by health programmes and services discussed to analyse their relevant features. Online supplemental table 1 provides data extracted from articles and can be found here: https://docs.google.com/ spreadsheets/d/1DUqwdFp06dRItagkxiiKaBqppnPshN1GbSNSbTJgAqI/edit?usp=sharing. Findings for each programme or service type are presented with a description of included studies and main outcome measures. Implications for policy, practice and further research as identified by the authors of the included articles are described for each health programme or service. Table 2 presents a summary of these results.

Services providing testing, prevention or treatment with antivirals for HIV or HCV

Many studies addressed the provision of antiviral treatment and testing $(\mathrm{n}=27,28 \%) .{ }^{21-47}$ The programmes and services all addressed treatment and prevention of HIV $(\mathrm{n}=17),{ }^{21}$ 22 24-26 28-303235-3840434647 HCV $(\mathrm{n}=7)^{232731} 33343941$ or both $(n=3) .{ }^{42445}$ Treatments provided through these programmes and services included ART (also referred to as highly active antiretroviral treatment (HAART)) $(\mathrm{n}=13),{ }^{22}$ 24-26 28-30 $3235373840 \mathrm{HCV}$ treatment (including cascade of care) $^{31} 33343941$ or DAA (n=9), ${ }^{23274445}$ postexposure prophylaxis $(\mathrm{n}=1),{ }^{43}$ pre-exposure prophylaxis $(\mathrm{n}=1)^{21}$ and antiretroviral treatment as prevention (TasP) $(\mathrm{n}=1) .{ }^{46}$ Services included HIV and HCV testing, 
Table 1 Description of included studies (study design, infectious disease, health programme or service, jurisdiction and population)

\begin{tabular}{|c|c|c|}
\hline & Description & $\begin{array}{l}\text { Total studies: } 97 \\
\text { n (\%) }\end{array}$ \\
\hline \multirow[t]{9}{*}{ Study design } & Cohort & $\begin{array}{l}45(46) \\
28 \text { prospective, } 17 \\
\text { retrospective }\end{array}$ \\
\hline & Commentary, report, non-systematic literature review, roundtable discussion & $14(14)$ \\
\hline & Qualitative (ethnoepidemiological, ethnographic, interviews, participatory research) & $12(12)$ \\
\hline & Cost-benefit and cost-effectiveness analysis & $7(7)$ \\
\hline & Randomised controlled trial (RCT)/protocol for RCT & $3(3)$ \\
\hline & Survey & $3(3)$ \\
\hline & Chart review - retrospective & $2(2)$ \\
\hline & Mixed methods & $2(2)$ \\
\hline & Systematic review & $2(2)$ \\
\hline \multirow{4}{*}{ Infections discussed } & $\mathrm{HCV}$ & $21(22)$ \\
\hline & $\mathrm{HIV}$ and $\mathrm{HCV}$ & $22(23)$ \\
\hline & Combinations of infectious diseases (HIV, HCV, HBV, cellulitis, bloodborne pathogens, STIs) & $9(9)$ \\
\hline & Infective endocarditis & $2(2)$ \\
\hline \multirow[t]{5}{*}{ Health programme/service } & $\begin{array}{l}\text { Services providing testing for and prevention or treatment with antivirals for HIV or HCV (ART/DAA/ } \\
\text { HAART/PEP/Seek and Treat Initiatives/TasP/POCT/PrEP) }\end{array}$ & $27(28)$ \\
\hline & Supervised injection facilities/safe injection facility/safe injection site & $19(20)$ \\
\hline & Medication treatment for opioid use disorder (MMT/OST/OAT/HAT/MAT) & $12(12)$ \\
\hline & Integrated infectious disease and addiction programmes & $10(10)$ \\
\hline & Needle exchange programmes/syringe exchange programmes/kit distribution programmes & $9(9)$ \\
\hline \multirow[t]{7}{*}{ Jurisdiction } & Multicountry & $5(5)$ \\
\hline & Canada & $5(5)$ \\
\hline & British Columbia (BC) & $63(65)$ \\
\hline & Ontario (ON) & $11(11)$ \\
\hline & Quebec (QC) & $9(9)$ \\
\hline & Alberta (AB) & $2(2)$ \\
\hline & Saskatchewan (SK) & $2(2)$ \\
\hline \multirow[t]{11}{*}{ Population within PWID } & All PWID & $48(49)$ \\
\hline & Persons with HIV & $18(19)$ \\
\hline & Persons with $\mathrm{HCV}$ & $6(6)$ \\
\hline & Persons in prison & $4(4)$ \\
\hline & PWID using specific health services (including NEP, SIF, OAT, pharmacies) & $4(4)$ \\
\hline & Not applicable & $3(3)$ \\
\hline & HIV and HCV positive & $2(2)$ \\
\hline & HIV negative & $2(2)$ \\
\hline & Indigenous & $2(2)$ \\
\hline & PWID with infective endocarditis & $2(2)$ \\
\hline & Hard to reach street youth and adults & $2(2)$ \\
\hline
\end{tabular}

Continued 
Table 1 Continued

\begin{tabular}{|c|c|}
\hline Description & $\begin{array}{l}\text { Total studies: } 97 \\
\text { n (\%) }\end{array}$ \\
\hline Female sex workers & $2(2)$ \\
\hline PWID leaving hospital due to self-discharge & $1(1)$ \\
\hline Vancouver Area Network of Drug Users volunteers & $1(1)$ \\
\hline \multicolumn{2}{|c|}{$\begin{array}{l}\text { ART, antiretroviral treatment; DAA, direct-acting antivirals; HAART, highly active antiretroviral treatment; HAT, heroin-assisted treatment; HBV, hepatitis B virus; HCV, hepatitis C virus; } \\
\text { IDU, injection drug use; MAT, medication-assisted treatment; MMT, methadone maintenance therapy; NEP, needle exchange programme; OAT, opioid agonist therapy; OST, opioid } \\
\text { substitution therapy ; PEP, postexposure prophylaxis; POCT, point-of-care testing; PrEP, pre-exposure prophylaxis; PWID, people who inject drugs; SIF, supervised injection facility; } \\
\text { STI, sexually transmitted infection; TasP, treatment as prevention. }\end{array}$} \\
\hline
\end{tabular}

including seek and treat initiatives $(n=2)^{36} 42$ and peeradministered point-of-care testing (POCT) $(\mathrm{n}=1){ }^{47}$ When indicated, the majority of health services were situated in the community $(n=17)$.

Some of the main outcome measures for these studies included experiences of PWID receiving $\mathrm{ART}^{24}$; factors related to testing, ART initiation, treatment adherence or discontinuation 212526293032353738 ; self-reported difficulties with taking $\mathrm{ART}^{22}$; and plasma viral load. ${ }^{21}{ }^{24}$ As with ART, adherence and willingness to use DAA was examined. ${ }^{44} 45$ Other studies examined patterns of mortality for PWID with HIV, ${ }^{28} 4042$ initiation of postexposure prophylaxis when delivered by registered nurses ${ }^{43}$ uptake of POCT in the community, ${ }^{47}$ ART initiation during a community wide TasP initiative ${ }^{46}$ and the use of a seek-and-treat programme to improve testing and treatment for marginalised PWID. ${ }^{36}$

Included articles also discussed HCV care. Studies aimed to characterise the HCV cascade of care ${ }^{3341}$ and examined outcomes of HCV treatment when received via physician or self-referral. ${ }^{39}$ Mathematical modelling studies were conducted to determine the burden of HCV in a variety of care scenarios, including increased testing and antiviral regimens $(n=3) .{ }^{23} 2741$ Two survey studies examined HCV care behaviours of physicians, where the main outcome was physician provision of HCV care to PWID. ${ }^{31} 34$

Authors identified implications for practice and policy, particularly emphasising the need to address social and structural factors that impede HIV and HCV testing, treatment initiation and adherence. To improve antiviral treatment adherence, authors suggested the need for improved housing stability for PWID and supportive housing models with harm reduction services. Other strategies to improve adherence included more welcoming clinical environments for PWID and integrated, multidisciplinary care to manage comorbid conditions and reduce barriers, which contribute to treatment discontinuation. Authors mentioned the need for targeted approaches to reach particularly marginalised PWID, such as females and sex workers. Additionally, authors mentioned scaling up ART, TasP, testing and care linkages. Strategies mentioned included expansion of communitybased testing and seek-and-treat campaigns for PWID unaware of HIV or HCV status and follow-up for patients who engage in postexposure prophylaxis services. The need for policies to support medication treatment for opioid use disorder (MOUD) services for inclusive HIV treatment strategies and to improve HCV treatment adherence were also highlighted.

Further research surrounding reasons for treatment discontinuation, factors associated with adherence, and the effect of incarceration on HIV treatment adherence and access was suggested. There is a need to understand how stigma and marginalisation create barriers in accessing treatment. Authors also suggested the evaluation of interventions like integrated, multidisciplinary HIV and HCV care, supportive housing models and addiction treatments. Further research is needed to determine the optimal timing of treatment for PWID receiving MOUD, and how these programmes affect antiviral treatment and access. There is a need to develop communitybased testing initiatives that use peers to reach PWID who may not seek testing and treatment in conventional healthcare settings.

\section{Supervised injection facilities}

Supervised injection facilities (SIFs), also known as safe injection facilities, or safe injection sites, were also represented in our sample as an important health programme addressing the prevention of infectious disease in PWID $(n=19,20 \%) .{ }^{48-66}$ Studies addressed the prevention of HIV $(\mathrm{n}=10), 50-5558606264$ HCV $(n=1)^{49}$ or both $(n=6),{ }^{56} 59616365$ with only two studies mentioning skin infections or abscesses in combination with HIV and HCV. ${ }^{47}$ Most SIF programmes identified were community-based $(\mathrm{n}=17)$; however, some discussed SIF use in hospitals $(\mathrm{n}=1),{ }^{49}$ clinics $(\mathrm{n}=1),{ }^{49}$ care facilities $(\mathrm{n}=1)^{55}$ and prisons $(\mathrm{n}=1) .{ }^{48}$ The majority of studies examined SIFs in Vancouver, British Columbia (BC) $(n=12)^{50-58626465}$ with a portion specifically looking at InSite $(n=7)$, Canada's first sanctioned SIF, which provided precedence for SIF expansion. ${ }^{51-54} 576265$ Other studies addressed SIFs in Ottawa $(\mathrm{n}=2)^{61}{ }^{63}$ or both Ottawa and Toronto $(\mathrm{n}=1)^{59}$ in Ontario $(\mathrm{ON})$; Montreal, Quebec $(\mathrm{QC})(\mathrm{n}=1)^{66}$; Saskatoon, Saskatchewan (SK) $(n=1)^{60}$; Drumheller, Alberta $(\mathrm{AB})(\mathrm{n}=1)^{48}$; and Canada broadly $(n=1) .{ }^{49}$ Main outcome measures for costeffectiveness and cost-benefit studies included prevented number of HIV and/or HCV infections and overdose deaths and others, such as quality-adjusted life years and life years gained. ${ }^{515545659606366}$ Considerations used in these models ranged from IDU population factors (eg, number of IDU in populations and prevalence of HIV infection), injectionrelated factors (eg, injections per IDU per year and injections 
Table 2 Policy, practice and research implications indicated in included studies and organised by health programme or service

\begin{tabular}{ll}
\hline Health programme/service & Policy and practice implications \\
\hline $\begin{array}{l}\text { Services providing testing, } \\
\text { prevention or treatment with } \\
\text { antivirals for HIV or HCV }\end{array}$ & $\begin{array}{l}\text { Address social and structural factors that impede HIV and HCV } \\
\text { testing, treatment initiation and adherence. }\end{array}$ \\
Scale up ART, TasP, testing and care linkages. & $\begin{array}{l}\text { Increase targeted approaches to reach marginalised PWID (eg, } \\
\text { females and sex workers). }\end{array}$ \\
& $\begin{array}{l}\text { Create policies to support MOUD services to promote inclusive } \\
\text { HIV treatment and to improve HCV adherence. }\end{array}$ \\
Suggested strategies to improve treatment adherence include: \\
1. Improved housing stability for PWID, supportive housing models \\
with harm reduction services. \\
2. Integrated, multidisciplinary care to manage comorbid conditions \\
and reduce barriers.
\end{tabular}

Gaps and research implications

Research reasons for treatment discontinuation, factors associated with adherence and the effect of incarceration on HIV treatment adherence and access.

- Understand how stigma and marginalisation create barriers in accessing treatment.

- Evaluate interventions like integrated, multidisciplinary HIV and HCV care, supportive housing models and addiction treatments.

- Determine the optimal timing of treatment for PWID receiving MOUD and how these programmes affect antiviral treatment and access.

Develop community-based testing initiatives that use peers to reach PWID who may not seek testing and treatment in conventional healthcare settings.

Supervised injection facilities Use of SIFs to deliver a wider range of services (eg, HIV testing and treatment).

Collect geographically specific and up-to-date data to inform policy.

Consider risk perceptions and priorities of PWID when designing harm reduction interventions.

- Amend legislation to create a more enabling environment for SIFs.

- Community support is fundamental for sustaining a SIF operation.

Medication treatment for opioid use disorder (MOUD)
Expansion of MOUD and harm reduction services by addressing system-level factors:

1. Decriminalisation policies.

2. Accessibility and funding.

3. Decrease barriers that limit physicians' ability to prescribe these medications

4. Enhance physician education in providing these services.

5. Improve referral systems.

6. Develop new pharmacotherapies for opioid use disorder.

Integrate MOUD services with infectious disease care and addiction treatment.

- Include PWID in policy-making surrounding the availability and delivery of MOUD services, including the expansion of these services as harm reduction in hospitals.

Integrated infectious disease and addictions services
Collaborative, multidisciplinary models, which include counselling and/or peer-based support groups extend beyond virological outcomes to improve social determinants of health. 
Table 2 Continued

\begin{tabular}{|c|c|c|}
\hline Health programme/service & Policy and practice implications & Gaps and research implications \\
\hline $\begin{array}{l}\text { Needle exchange } \\
\text { programmes }\end{array}$ & $\begin{array}{l}\text { Expansion of NEPs and kit distribution programmes, particularly } \\
\text { in prisons and hospitals. } \\
\text { Decentralise NEPs, promoting peer-run initiatives and diversify } \\
\text { distribution methods to reach more marginalised PWID. } \\
\text { Include PWID and community members in programmatic } \\
\text { decision making and consider local context when initiating } \\
\text { NEPs. }\end{array}$ & $\begin{array}{l}\text { Gaps in evaluation of NEPs. } \\
\text { Implement ongoing evaluation and monitoring of } \\
\text { programmes. } \\
\text { Examine different models of distribution across settings } \\
\text { and cultural contexts. }\end{array}$ \\
\hline $\begin{array}{l}\text { Broad harm reduction } \\
\text { strategies }\end{array}$ & $\begin{array}{l}\text { Expansion of harm reduction services, increased financial } \\
\text { support for these services and their combination with HIV and } \\
\text { HCV testing and treatment strategies, equity of access. } \\
\text { Advance peer-based models of care. } \\
\text { Reassess punitive drug policies. } \\
\text { Improve evaluation and monitoring for harm reduction } \\
\text { programmes. } \\
\text { Support initiatives that address social harms affecting PWID and } \\
\text { the social determinants of health. } \\
\text { Involve marginalised groups of PWID (eg, youth and Indigenous) } \\
\text { in programme planning. }\end{array}$ & $\begin{array}{l}\text { Indigenous people in Canada may lack access to primary } \\
\text { care and HCV testing. } \\
\text { Since many provinces do not collect ethnicity data, } \\
\text { national data on HCV prevalence does not extend to } \\
\text { Indigenous communities. } \\
\text { Understand HCV prevalence and determinants related to } \\
\text { HCV transmission among Indigenous PWID. } \\
\text { Understand youth engagement and access to harm } \\
\text { reduction services. } \\
\text { Examine injection equipment distribution policies and } \\
\text { coverage and understand the risks from sharing injection } \\
\text { equipment using robust study designs. }\end{array}$ \\
\hline $\begin{array}{l}\text { Mobile care initiatives and } \\
\text { telehealth }\end{array}$ & $\begin{array}{l}\text { Peer-led mobile initiatives play an important role in extending the } \\
\text { reach of conventional public health programmes. } \\
\text { Important to empower clients to make changes, by providing } \\
\text { resources within an atmosphere of mutual respect, education, } \\
\text { support, participation, commitment, power sharing. } \\
\text { Multidisciplinary telehealth approaches can engage and retain } \\
\text { patients in remote areas in the treatment of HCV. } \\
\text { Culturally safe interventions that address the barriers to HIV } \\
\text { prevention while supporting the strength of populations (eg, } \\
\text { young Indigenous people) are urgently needed. }\end{array}$ & $\begin{array}{l}\text { How specific characteristics of mobile outreach } \\
\text { programmes may facilitate entry into inpatient addiction } \\
\text { treatment or connect women to other services. } \\
\text { Methods of including and evaluating community } \\
\text { partnering, collaborating in healthcare delivery models } \\
\text { for PWID. }\end{array}$ \\
\hline Peer-delivered services & $\begin{array}{l}\text { Improve delivery of care for PWID and address lack of trust } \\
\text { and unfamiliarity with the healthcare system and healthcare } \\
\text { professionals. } \\
\text { Enable delivery of care and infectious disease prevention efforts } \\
\text { to harder-to-reach, more marginalised PWID. } \\
\text { Legal and regulatory frameworks need to accommodate assisted } \\
\text { injections and consideration for peer-based delivery models. }\end{array}$ & $\begin{array}{l}\text { Need for harm reduction initiatives to assess their } \\
\text { accessibility to less autonomous PWID. }\end{array}$ \\
\hline $\begin{array}{l}\text { Treatment of infective } \\
\text { endocarditis }\end{array}$ & Integrate addiction treatment with infectious disease care. & $\begin{array}{l}\text { Gaps in understanding factors associated with PWID } \\
\text { mortality. }\end{array}$ \\
\hline $\begin{array}{l}\text { Other health programmes and } \\
\text { services }\end{array}$ & $\begin{array}{l}\text { Increased access to harm reduction and addictions services, } \\
\text { urgent primary care, immunisations, ambulatory and integrated } \\
\text { care, and stable housing are needed to optimise health } \\
\text { outcomes, reduce substance use-related deaths and decrease } \\
\text { hospital utilisation. } \\
\text { Incorporate mental health interventions with harm reduction } \\
\text { services to support behaviour changes. }\end{array}$ & $\begin{array}{l}\text { Further studies on reasons for hospital admissions and } \\
\text { ER use in PWID/PLHIV. } \\
\text { Determine effectiveness of mental health interventions in } \\
\text { the community. } \\
\text { Determine effectiveness of interventions in ER settings to } \\
\text { prevent further ER visits and admissions. }\end{array}$ \\
\hline
\end{tabular}

ART, antiretroviral treatment; ER, emergency room; HCV, hepatitis C virus; IDU, injection drug use; MOUD, medication treatment for opioid use disorder; NEPs, needle exchange programmes; PLHIV, people living with HIV; PWID, people who inject drugs; SIF, supervised injection facility; TasP, treatment as prevention.

with shared equipment) and facility factors (eg, annual operating cost and number of injections per year at site). Other outcome measures involved self-reported use or potential use of SIFs by IDU, perspectives on use of and access to SIFs and benefits and acceptability of SIFs. Authors described the benefits of SIFs as improving access to care, reducing public healthcare costs and reducing IDU/IVDU-related harms.

Authors discussed policy and practice implications of SIFs. SIFs were discussed as saving lives from overdose deaths, decreasing infections, improving health outcomes, providing points of contact for the highest risk PWID, and facilitating access to care. However, it was pointed out that SIFs could also be used to deliver a wider range of services, including HIV testing and treatment. Even though every study showed that SIFs were cost-saving in the Canadian contexts in which they were conducted, there was variability in the service models. Other benefits of SIFs included enhanced public order, fewer public injections and reduced injection-related litter. For implementation of SIFs, the authors recommended consideration of risk perceptions and priorities of IDUs when designing harm reduction interventions, the need to create a more enabling environment for SIFs through amendment of federal legislation and highlighted that community support is fundamental for sustaining a SIF.

Research implications and gaps in research were also described. These included the need to routinely collect accurate, geographically specific and up-to-date data in order to inform policy; understand harm reduction needs of people who inject alone in private residences, social determinants of IDUs, individual or context-specific barriers and reasons for not accessing SIF services; and social and behavioural effects of SIFs (eg, sharing practices). Several points were noted regarding the evaluation of SIF services. There is a need to develop and implement monitoring and evaluation 
programmes for SIFs once they open and to consider more than one potential benefit in cost-benefit analysis for public health. These considerations could include diagnostics, immunisation, referral to detoxification facilities, decreased use of other medical services and assessing expansion of services to determine cost-benefits of increased operating hours. Authors noted the challenge in evaluating an intervention without a traditional control group and the need to consider intermediate outcomes, such as changes in injecting practices, along with epidemiological data. There is also a gap in understanding needs and use of SIFs by street-involved youth.

\section{Medication treatment for opioid use disorder (MOUD)}

A number of studies $(\mathrm{n}=12,12 \%)$ addressed the provision of MOUD, sometimes referred to as opioid agonist therapy (OAT) ${ }^{67}$ opioid substitution therapy ${ }^{68}{ }^{69}$ or medication-assisted treatment (MAT) ${ }^{70}$ with seven studies focused specifically on methadone maintenance therapy $(\mathrm{MMT})^{15}{ }^{71-76}$ and one on heroin-assisted treatment (HAT). ${ }^{77}$ Five studies addressed HCV, ${ }^{67} 69717576$ four addressed $\mathrm{HIV}^{72-74} 77$ and three addressed both HCV and HIV. ${ }^{15} 6870$ The programmes were situated in communities $(\mathrm{n}=5),{ }^{70} 72737576$ hospitals $(\mathrm{n}=1),{ }^{15}$ clinics $(\mathrm{n}=2){ }^{6774}$ or unspecified locations $(n=4) .{ }^{68} 697177$ All programmes were in BC $(n=10)$, except two, which included multiple countries. ${ }^{6770}$ Community provision of MMT in BC was specifically discussed as methadone is readily available through primary care physicians and dispensed through community pharmacies in this jurisdiction. ${ }^{74}$ These programmes were examined as a protective factor for limiting HIV and HCV transmission. Authors examined the effect of these programmes on HIV and HCV care, including access to a regular physician. Studies also examined eligibility of PWID for HAT in the local community, perceptions of HCV care among physicians working in MOUD clinics and use of prescription opioids in hospitals to prevent patient-initiated discharge. Studies found that these types of programmes improved regularity of access to care and antiviral treatment outcomes and reduced risk of infection and other IDU-related harms.

Authors identified the need for expansion of MOUD and harm reduction services by addressing system-level factors, such as decriminalisation policies, accessibility and funding of services, decreasing barriers that limit physicians' ability to prescribe these medications, enhancing physician education in providing these services, improving referral systems and developing new pharmacotherapies for opioid use disorder. Authors also suggested the integration of MOUD services with infectious disease care and addiction treatment. PWID should be included in policy-making surrounding the availability and delivery of MOUD services, including the expansion of these services as harm reduction in hospitals. Future research is needed to assess the impact of MOUD in combination with other harm reduction services and counselling, and their effects on infectious disease care, reinfection and treatment retention and adherence. Specifically, experimental designs are needed, and studies need to examine certain population groups, such as women. Other avenues of investigation include exploring perspectives of hospital staff regarding care of PWID and the potential integration of harm reduction services into hospitals.

\section{Integrated infectious disease and addictions services}

Programmes $(n=10)$ incorporated infectious disease treatment with addictions treatment or other services, such as counselling. ${ }^{78-87}$ Studies were conducted in Vancouver, BC $(\mathrm{n}=7),{ }^{7879}{ }^{81-8387}$ Montreal, QC $(\mathrm{n}=2),{ }^{80} 84$ and Kingston, ON $(\mathrm{n}=1) .{ }^{86}$ Programmes were community based $(\mathrm{n}=2),{ }^{83} 84$ in established community health centres $(n=4),{ }^{81}{ }^{85-87}$ offered through multiple sites $(n=3)^{78-80}$ or not specified $(n=1) .82$ Studies addressed HIV (n=3), ${ }^{81} 8285$ HCV (n=5), ${ }^{79} 80848687$ or HIV and HCV $(n=2){ }^{78} 83$ Main outcome measures can be classified as use of services $(n=5)$, such as documented or self-reported use of existing integrated services, and how use of services shaped access to and engagement with other supportive care services, behaviour change $(n=2)$ and treatment response $(n=3)$. Treatment completion, post-treatment follow-up and reinfection were other outcomes used. Study findings supported a multidisciplinary model of treatment, which included medical, psychiatric, social support and access to more individualised care.

Authors stated that concurrent mental health and nonprescribed drug use may act as barriers to adequate HIV care, and changes to the structural-environmental context of services (such as incorporating nonprescribed drug use within a harm reduction approach) can improve engagement with care among people living with HIV (PLHIV) who use drugs. The policy and practice implication that most resonated across these studies was the benefits of collaborative, multidisciplinary models, which include counselling and/or peer-based support groups. These models of HCV or HIV treatment in IDUs may extend beyond virological outcomes to improve social determinants of health. Specifically, receiving HCV treatment was associated with lower likelihood of reporting IDU, ${ }^{80}$ and integrating HCV treatment within primary care and addictions clinics, which treat individuals already engaged with MOUD, may help improve follow-up after treatment. ${ }^{79}$

Future research could examine the impact of policy change on uptake of HCV and/or HIV treatment and care among PWID. Authors also called for research on the impact of diverse, innovative, integrated delivery strategies to improve uptake of HCV and/or HIV care in PWID and to investigate which aspects of care are likely to support changes in drug use patterns. Further exploratory studies recommended including individual's ideas, beliefs and feelings after HCV treatment and reasons for not returning for care or PWID experiences of effects of integrated care models on health and social inequities.

\section{Needle exchange programmes}

NEPs (also known as clean needle programmes and syringe exchange programmes) and harm reduction kit distribution programmes were also identified $(n=9,9 \%){ }^{88-96}$ Studies addressed HIV (n=3), ${ }^{92} 92$ or both HIV and 
HCV (n=4), ${ }^{88} 909496$ with the remaining studies broadly addressing blood-borne infections and cellulitis. ${ }^{89} 93$ These studies described NEPs, implementation of a kit distribution programme $(\mathrm{n}=1)^{89}$ and introduction of NEPs in prisons $(\mathrm{n}=3){ }^{88} 9096$ We included two prospective cohort studies, which examined the relationship between NEP use, HIV seroconversion and rates of syringe borrowing and lending, and both reported a reduction in HIV incidence among PWID. ${ }^{92} 95$ One RCT was included, which evaluated a theory-based intervention to increase NEP use. Participants in the experimental group used fewer borrowed syringes compared with the control group (relative risk (RR): 0.47, 95\% CI 0.28 to $0.79 ; \mathrm{p}=0.004) .{ }^{94}$ This effect was no longer present 3 months later.

Authors identified implications for practice, policy and research. The included studies called for expansion of NEPs and kit distribution programmes, particularly in prisons and hospitals. Decentralising NEPs, promoting peer-run initiatives and diversifying distribution methods are needed to reach more marginalised PWID. Authors also indicated the importance of including PWID and community members in programmatic decision making and consideration of local context when initiating NEPs. Researchers found gaps in evaluation of NEPs, therefore future research should focus on ongoing evaluation and monitoring of programmes. Authors also indicated the need to examine different models of distribution across settings and cultural contexts.

\section{Broad harm reduction strategies}

We identified six studies that provided reviews, recommendations or assessments of a range of harm reduction services. ${ }^{97-102}$ Studies focused on HIV (n=2), ${ }^{99} 100 \mathrm{HCV}$ $(n=2)^{97} 98$ or both \pm HBV $(n=2) .{ }^{101} 102$ One mathematical modelling study created a community model to simulate the effect of strategies on HIV prevalence, including providing clean syringes, introduction of SIFs, introduction of TasP to improve treatment initiation and retention and increased HIV testing. ${ }^{100}$ One qualitative study examined factors influencing injection and perceived barriers to injection cessation among marginalised youth, focusing on HIV. The study mentioned health programmes and harm reduction services, including MOUD, drug treatment programmes and social support programmes. ${ }^{99}$ These studies discussed HIV, HCV and HBV and highlighted efforts, recommendations and challenges to improving harm reduction efforts. One of these studies specifically discussed community-driven programmes to improve HCV testing and care in Indigenous communities who are at greater risk for adverse IDU-related health outcomes. ${ }^{98}$

These studies identified a broad range of implications for policy and practice. The authors support the expansion of harm reduction services, increased financial support for these services and their combination with HIV and HCV testing and treatment strategies. Additionally, authors indicated the advancement of peer-based models of care, the reassessment of punitive drug policies and the need for improved evaluation and monitoring for harm reduction programmes. Increased support is needed for initiatives that address social harms affecting PWID and the social determinants of health. Equity of access to harm reduction services should be ensured. Authors specifically mentioned the need to involve marginalised groups of PWID, youth and Indigenous communities in planning harm reduction programmes. Youth should be included in policy decisions, with targeted services to improve access to care for this group. Similarly, Indigenous PWID require more targeted services that include links between on-reserve and off-reserve programmes and to Indigenous PWID in prison.

Authors also identified gaps and associated research implications related to youth and Indigenous PWID. Indigenous people in Canada may lack access to primary care and HCV testing. Since many provinces do not collect ethnicity data, national data on HCV prevalence does not extend to Indigenous communities. Further research is needed to understand HCV prevalence and determinants related to HCV transmission among Indigenous PWID. Further study is also needed to understand youth engagement and access to harm reduction services. Finally, it was noted that few studies examine injection equipment distribution policies and coverage, and more research is needed to understand the risks from sharing injection equipment using robust study designs.

\section{Mobile care initiatives and telehealth}

Mobile care initiatives and telehealth seek to expand the reach of traditional programmes. Studies included mobile care initiatives $(n=3)^{103-105}$ and telehealth $(n=2)^{106} 107$ and focused on HIV $(n=1),{ }^{104} \mathrm{HCV}(\mathrm{n}=1),{ }^{106} \mathrm{HIV}$ and HCV $(n=1),{ }^{107}$ or STIs in addition to HIV $(n=2) .{ }^{103} 105$ Two of the three mobile care initiatives were peer led. ${ }^{103} 104$ Mobile care initiatives used peer volunteers to distribute sterile injection equipment and to provide harm reduction education and outreach. Another mobile care initiative deployed nurses to provide medical attention in addition to equipment and education. ${ }^{105}$ Main outcomes measured for mobile care initiatives included use of the programme in the previous 6 months and description of roles and contributions of healthcare staff delivering the programme.

Mobile health and telemedicine initiatives included efforts to support HCV and HIV care remotely for those with difficulty accessing care. ${ }^{106} 107$ The telehealth programmes measured HIV propensity scores at 6 months and sustained viral response as their main outcome measures. These studies also evaluated secondary drug treatment outcomes and use of related health services.

Implications for policy and practice included that peer-led mobile initiatives can play an important role in extending the reach of conventional public health programmes. Specifically for hard-to-reach female sex workers who use drugs, unsuccessful attempts to access drug treatment can be associated with increased odds of violence. Mobile outreach programmes can serve a role in HIV and STI prevention. Overall, it is important to empower clients to make changes, by providing resources, skills and opportunities within an atmosphere of mutual trust and respect, education and support, participation and commitment, and power-sharing. 
Telehealth saved patients time, travel and missed work days with high levels of satisfaction. Multidisciplinary telehealth approaches can engage and retain patients in remote areas in the treatment of HCV. Lastly, innovative and culturally safe interventions that address the barriers to HIV prevention while supporting the strength of populations (eg, young Indigenous people) who use drugs are urgently needed. Future research could concentrate on understanding how specific characteristics of mobile outreach programmes may facilitate entry into inpatient addiction treatment or connect women to other services. Research could also address methods of including and evaluating community partnering, coordinating and collaborating in current and future healthcare delivery models for PWID.

\section{Peer-delivered services}

Studies discussed peer delivered services such as counselling and testing $(\mathrm{n}=2)^{108} 109$ and peer-delivered injections $(\mathrm{n}=1) .{ }^{110}$ These include one cohort study ${ }^{109}$ and two qualitative studies ${ }^{108}{ }^{110}$; all programmes were conducted in a community setting in Vancouver, BC. These addressed HIV $(\mathrm{n}=1)^{109}$ or both HIV and HCV $(\mathrm{n}=2){ }^{108} 110$ The studies explored experiences as a peer IDU with the Vancouver Area Network of Drug Users (VANDU), how VANDU shaped the social context and injection practices in that community and willingness to receive peer-delivered services. These studies indicate that peer-based services can improve delivery of care for PWID and address issues such as lack of trust and unfamiliarity with the healthcare system and healthcare professionals. ${ }^{109}$ Additionally, peer-delivered services enabled delivery of care and infectious disease prevention efforts to harder-to-reach, more marginalised PWID. For example, one study examining PWID's use of an unsanctioned peerdelivered injections service indicated that those who require assistance injecting, including women and people with disability, are at greater risk of harm and experience barriers that inhibit their use of sanctioned SIFs. These findings underscore the need for harm reduction initiatives to assess their accessibility to certain, less autonomous PWID populations. ${ }^{110}$ Peer-led organisations for IDU, such as VANDU, may also give PWID a political voice. Lastly, legal and regulatory frameworks need to accommodate assisted injections and consideration for peer-based delivery models.

\section{Treatment of infective endocarditis}

Only two studies (2\%) addressed the treatment of infective endocarditis in a hospital setting, comparing mortality associated with surgical versus medical management. ${ }^{111} 112$ The main outcomes of these studies were the incidence of death 2 years following diagnosis or all-cause mortality. Rodger and others additionally collected data related to site of infection, complications and referral to addiction treatment services. ${ }^{11}$ This study showed that surgery was related to lower mortality, ${ }^{111}$ while the other found no difference. ${ }^{112}$ Neither study looked at the prevention of infectious diseases or quality improvement for the delivery of these services. Both studies identified the need for integration of addiction treatment with infectious disease care, including multidisciplinary care teams and patient commitment to addiction rehabilitation. Authors suggested further research include increased use of addiction treatment and noted gaps in understanding of factors associated with PWID mortality.

\section{Other health programmes and services}

One study included a randomised controlled trial in QC on motivational interviewing (MI) for high risk IDU behaviours, which showed that both MI and educational interviewing decreased risk behaviours, but individuals in the MI group had lower odds of risk behaviours at 6 months. ${ }^{113}$ A cohort study in BC evaluated first time emergency department use by PWID along with most common diagnoses, admissions and discharge data. ${ }^{114} \mathrm{~A}$ mixed methods study provided a qualitative description of laws, policies, attitudes, practices and behaviours surrounding the possibility of expanding pharmacy services for PWID in six countries. ${ }^{115}$ Lastly, Jaworsky et al. performed a chart review to describe trends in admission in a dedicated HIV/AIDS ward in a tertiary hospital in BC, which was repurposed in 2014 and expanded to include HIV-negative individuals with infectious conditions arising from addictions comorbidities. ${ }^{116}$

These papers highlight that increased access to harm reduction and addictions services, urgent primary care, immunisations, ambulatory and integrated care, and stable housing are needed in the PWID population to optimise health outcomes, reduce substance use-related deaths and decrease hospital utilisation. Macrochanges, mesochanges, and microchanges in policies, laws, attitudes and behaviours are needed in order to decrease barriers for PWID to access services. Also, mental health interventions could be incorporated into harm reduction services to support behaviour changes. Authors called for further studies on reasons for hospital admissions and emergency room (ER) use in PWID/PLHIV. Lastly, studies are needed to determine effectiveness of mental health interventions in the community and interventions in ER settings to prevent further ER visits and admissions.

\section{DISCUSSION \\ Main findings}

We identified a number of health programmes and services addressing the prevention and management of infectious diseases in PWID in Canada. These included testing and management of HIV and HCV, SIFs, MOUD, integrated infectious disease and addiction programmes, NEPs, harm reduction strategies broadly, mobile care initiatives, peerdelivered services and management of IDU-related bacterial infections in hospital. A broad range of study types and grey literature were included, allowing for elucidation of key recommendations for policy, practice and research.

Discussion of HIV and HCV infections far outweighed other IDU-related infectious diseases. The majority of the health programmes and services included in our study addressed the provision of antiviral treatment and viral testing. Studies addressed the cost-benefit and cost-effectiveness of SIFs. MOUD programmes were shown to reduce risk of infection 
and improve antiviral treatment outcomes. Studies discussed harm reduction services broadly, calling for the expansion and combination of these services with HIV and HCV treatment strategies. Interdisciplinary or integrated health programmes were shown to provide comprehensive care to PWID. Additionally, we found health programmes that attempted to reach more marginalised PWID through telehealth and mobile care initiatives. Peer-delivered services, such as testing, counselling and assisted injections, removed barriers to care for PWID who distrust healthcare providers or require assistance injecting. Only two included studies addressed treatment of infective endocarditis.

\section{Strengths and limitations of study}

This study employed a systematic integrative review design that allowed for the inclusion of empirical, non-empirical and grey literature. Using this study design enabled a broad overview of health programmes and services available for PWID in Canada. Additionally, documents were screened independently by two reviewers, improving reproducibility and limiting bias. Similarly, data extraction and quality assessment of included studies were performed independently by two data collectors.

Despite these strengths, this study has some limitations. An integrative review limits our study to published literature, which may exclude programmes or services not published. Additionally, our study sought to provide an overview of health programmes and services for PWID in Canada but did not formally evaluate the effectiveness of the included programmes and services in preventing or treating infectious disease in PWID. Our review was limited to Canada, reducing the generalisability of these results, however improving the specificity of policy and practice recommendations derived from these results. Limitations were quite diverse due to the range of study types included in this review. Many of the cohort studies indicated that their sample was not random due to the use of previously established cohorts and, therefore, may not be generalisable to larger populations. Similarly, qualitative studies indicated a lack of generalisability, since experiences are specific to the PWID included in the study. Studies that relied on PWID self-report indicated limitations in the validity of the data due to social desirability bias. Cost-benefit analysis and mathematical modelling studies were limited by the assumptions, which cannot be verified, necessary for mathematical calculations, which may result in over or underestimations of disease transmission or cost-savings.

\section{Fit within literature}

This study provides an overview of health programmes and services relating to infectious disease care for PWID in Canada. While there are a number of systematic reviews examining interventions to treat HIV and HCV in PWID, ${ }^{5} 68117118$ our study is unique by focusing on the Canadian context, including all IDU-related infectious diseases, and including a variety of study designs. Other reviews examining the prevention and treatment of infectious disease in PWID found an emphasis on harm reduction efforts and HIV or HCV care.
The included studies indicate the benefits of harm reduction efforts and support their increased use in communities and across other sites, including hospitals and prisons. Most studies in Canada are also from Vancouver, BC, which has a long history of empowering and working with PWID. While other jurisdictions in Canada can learn from Vancouver's work, it is important to conduct research in other cities and provinces to account for contextual differences.

\section{Recommendations for practice and research}

The included studies indicate the advantages of multifaceted care programmes for PWID, which include harm reduction, medical and pharmaceutical treatments, social support and education. These programmes target the social determinants of health, improving the underlying social and structural barriers that prevent PWID from accessing and adhering to treatments or health programmes. ${ }^{81} 828586$ Notably, the included studies call for exploratory work in facilitators and barriers to treatment and care, more robust study designs, and attention to contextual factors and more complex interventions.

There is a need to address social and structural factors that impede continued care for PWID. These factors relate to the social determinants of health and include criminalisation of IDU, stigma and discrimination of PWID when accessing health programmes or services and lack of funding for harm reduction services. Recommendations include the introduction of supportive housing models for PWID to enable greater adherence and access to infectious disease treatment or MOUD. Multidisciplinary or integrated care models for infectious disease treatment also provide PWID with more comprehensive care, addressing medical, social and mental health challenges.

Targeted programmes and services for marginalised groups of PWID, such as street-involved adults and youth, sex workers and Indigenous peoples, are needed. NEPs, mobile care initiatives, telehealth and peer-delivered services sought to improve access to care for these more marginalised groups. Advancing peer models of care may decrease the stigmatisation and marginalisation experienced by PWID and reduce barriers to accessing care. This is a prominent and promising area for further research and implementation.

A pressing consideration for further research is improved evaluation and monitoring of health programmes and services using more robust research designs. Further research is needed to understand specific needs of PWID across settings and cultural contexts. These may elucidate reasons for not accessing services or returning to care and ideas and beliefs of PWID regarding health programmes and services.

The majority of studies addressed HIV and HCV, which are mainly managed in outpatient settings, given the advancements in treatment for these two infectious diseases. A related project by this group is a chart review of PWID admitted to hospital to assess the types of infectious diseases and concerns around patient-initiated discharges. Preliminary findings show there is little overlap in these two studies, highlighting the disconnect between community and 
hospital-based initiatives that ensure continuity of care in this population. There are few included studies addressing IDUrelated bacterial infections, despite their prevalence among PWID and leading cause of long-term hospitalisations and emergency department use. ${ }^{114119} 120$ This gap indicates the need for further research on PWID care in hospital and health programmes which link the community and hospital settings.

\section{CONCLUSIONS}

There are a variety of health programmes and services addressing the prevention and management of infections in PWID in Canada. Programmes and services should be expanded across geographic settings, healthcare settings and populations of PWID, specifically more marginalised PWID. Improving infectious disease care for PWID requires attention to social and structural barriers and inclusion of PWID in programmatic decision making.

\section{Author affiliations}

${ }^{1}$ Department of Global Health, McMaster University, Hamilton, Ontario, Canada ${ }^{2}$ Department of Health Research Methods, Evidence and Impact, McMaster University, Hamilton, Ontario, Canada

${ }^{3}$ Department of Undergraduate Medical Education, McMaster University, Hamilton, Ontario, Canada

${ }^{4}$ School of Health Sciences, Jiangsu Institute of Commerce, Nanjing, Jiangsu, China ${ }^{5}$ Department of Surgery, McMaster University, Hamilton, Ontario, Canada

${ }^{6}$ Faculty of Pharmacy, Eastern Mediterranean University, Famagusta, North Cyprus, Cyprus

${ }^{7}$ Department of Family Medicine, McMaster University, Hamilton, Ontario, Canada

${ }^{8}$ Center for Health Economics and Policy Analysis, McMaster University, Hamilton, Ontario, Canada

${ }^{9}$ Department of Infectious Diseases, Hamilton Health Sciences, Hamilton, Ontario, Canada

${ }^{10}$ Centre for Health Economics and Policy Analysis (CHEPA), McMaster University, Hamilton, Ontario, Canada

Acknowledgements Annie Wang was involved in the initial discussions of the methods for this study.

Contributors EA conceived of the topic. CL, LM, ML, RL, J-ET and DK helped develop the research question and methods. KB, SJ, SP, YQ, HS, MQ and AH helped develop the search strategy and conducted data collection. KB and EA conducted data analysis and wrote the initial manuscript. All authors provided substantive comments and approved the final manuscript.

Funding The authors have not declared a specific grant for this research from any funding agency in the public, commercial or not-for-profit sectors.

Competing interests None declared.

Patient consent for publication Not required.

Provenance and peer review Not commissioned; externally peer reviewed.

Data availability statement All data relevant to the study are included in the article or uploaded as supplementary information. All data generated or analyzed during this study are included in this published article.

Supplemental material This content has been supplied by the author(s). It has not been vetted by BMJ Publishing Group Limited (BMJ) and may not have been peer-reviewed. Any opinions or recommendations discussed are solely those of the author(s) and are not endorsed by BMJ. BMJ disclaims all liability and responsibility arising from any reliance placed on the content. Where the content includes any translated material, BMJ does not warrant the accuracy and reliability of the translations (including but not limited to local regulations, clinical guidelines, terminology, drug names and drug dosages), and is not responsible for any error and/or omissions arising from translation and adaptation or otherwise.
Open access This is an open access article distributed in accordance with the Creative Commons Attribution Non Commercial (CC BY-NC 4.0) license, which permits others to distribute, remix, adapt, build upon this work non-commercially, and license their derivative works on different terms, provided the original work is properly cited, appropriate credit is given, any changes made indicated, and the use is non-commercial. See: http://creativecommons.org/licenses/by-nc/4.0/.

ORCID iDs

Katrina Bouzanis http://orcid.org/0000-0002-0059-1942

Lawrence Mbuagbaw http://orcid.org/0000-0001-5855-5461

Elizabeth Alvarez http://orcid.org/0000-0003-2333-0144

\section{REFERENCES}

1 Jacka B, Larney S, Degenhardt L, et al. Prevalence of injecting drug use and coverage of interventions to prevent HIV and hepatitis $C$ virus infection among people who inject drugs in Canada. Am J Public Health 2020;110:45-50.

2 Wilson M, Waddell K, Lavis J. Evidence brief: preventing and managing infectious diseases among people who inject drugs in Ontario. Ontario: Hamilton, 2019.

3 Public Health Agency of Canada. Summary of key findings from I-TRACK phase 3. Ottawa 2014.

4 Challacombe L. The epidemiology of HIV in people who inject drugs in Canada. CATIE, 2019.

5 Gowing LR, Farrell M, Bornemann R, et al. Brief report: methadone treatment of injecting opioid users for prevention of HIV infection. $J$ Gen Intern Med 2006;21:193-5.

6 MacArthur GJ, van Velzen E, Palmateer N, et al. Interventions to prevent HIV and hepatitis $C$ in people who inject drugs: a review of reviews to assess evidence of effectiveness. Int J Drug Policy 2014;25:34-52.

7 MacArthur GJ, Minozzi S, Martin N, et al. Opiate substitution treatment and HIV transmission in people who inject drugs: systematic review and meta-analysis. BMJ 2012;345:e5945.

8 Abdul-Quader AS, Feelemyer J, Modi S, et al. Effectiveness of structural-level needle/syringe programs to reduce HCV and HIV infection among people who inject drugs: a systematic review. AIDS Behav 2013;17:2878-92.

9 Kerr T, Kimber J, Debeck K, et al. The role of safer injection facilities in the response to HIVIAIDS among injection drug users, 2007.

10 Platt L, Minozzi S, Reed J, et al. Needle syringe programmes and opioid substitution therapy for preventing hepatitis $\mathrm{C}$ transmission in people who inject drugs. Cochrane Database Syst Rev 2017:137.10.1002/14651858.CD012021.pub2

11 Coffin CS, Fung SK, Alvarez F. Management of hepatitis B virus infection: 2018 guidelines from the Canadian association for the study of the liver and association of medical microbiology and infectious disease Canada. Can Liver J 2018.

12 Habib G, Lancellotti P, Antunes MJ, et al. The 2015 ESC guidelines for the management of infective endocarditis. Eur Heart $J$ 2015;36:3036-7.

13 Shah H, Bilodeau M, Burak KW. The management of chronic hepatitis C: 2018 guideline update from the Canadian association for the study of the liver. Can Med Assoc J 2018;190:E677-87.

14 World Health Organization. Consolidated guidelines on the use of antiretroviral drugs for treating and preventing HIV infection [online]. World Health Organization, 2018. http://www.who.int/hiv/pub/arv/ arv-2016/en/

15 McNeil R, Small W, Wood E, et al. Hospitals as a "risk environment": an ethno-epidemiological study of voluntary and involuntary discharge from hospital against medical advice among people who inject drugs. Soc Sci Med 2014;105:59-66.

16 Ti L, Milloy M-J, Buxton J. Factors associated with leaving Hospital against medical advice among people who use illicit drugs in Vancouver, Canada. Gao C-Q, editor. PLoS One 2015;10.

17 Whittemore R, Knafl K. The integrative review: updated methodology. J Adv Nurs 2005;52:546-53.

18 Alvarez E, Joshi S, Lokker C, et al. Health programmes and services addressing the prevention and management of infectious diseases in persons who inject drugs in Canada: a systematic integrative review protocol. BMJ Open 2020;10:e035188.

19 Tricco AC, Lillie E, Zarin W, et al. PRISMA extension for scoping reviews (PRISMA-ScR): checklist and explanation. Ann Intern Med 2018;169:467-73.

20 Sirriyeh R, Lawton R, Gardner P, et al. Reviewing studies with diverse designs: the development and evaluation of a new tool. J Eval Clin Pract 2012;18:746-52. 
21 Bazzi AR, Drainoni M-L, Biancarelli DL, et al. Systematic review of HIV treatment adherence research among people who inject drugs in the United States and Canada: evidence to inform pre-exposure prophylaxis (PreP) adherence interventions. BMC Public Health 2019;19:31.

22 Yeung B, Mohd Salleh NA, Socías E, et al. Prevalence and correlates of reporting difficulty taking antiretroviral treatment among HIV-positive illicit drug users in Vancouver, Canada: a longitudinal analysis. AIDS Behav 2019;23:1250-7.

23 Rozada I, Coombs D, Lima VD. Conditions for eradicating hepatitis $C$ in people who inject drugs: a fibrosis aware model of hepatitis $C$ virus transmission. J Theor Biol 2016;395:31-9.

24 Small W, Milloy MJ, McNeil R. Plasma HIV-1 RNA viral load rebound among people who inject drugs receiving antiretroviral therapy (art) in a Canadian setting: an ethno-epidemiological study. AIDS Res Ther 2016:13-26.

25 Bach P, Wood E, Dong H, et al. Association of patterns of methadone use with antiretroviral therapy discontinuation: a prospective cohort study. BMC Infect Dis 2015;15:537.

26 Joseph B, Kerr T, Puskas CM, et al. Factors linked to transitions in adherence to antiretroviral therapy among HIV-infected illicit drug users in a Canadian setting. AIDS Care 2015;27:1128-36.

27 Lima VD, Rozada I, Grebely J, et al. Are interferon-free direct-acting antivirals for the treatment of HCV enough to control the epidemic among people who inject drugs? PLoS One 2015;10:e0143836.

28 Nosyk B, Min JE, Evans E, et al. The effects of opioid substitution treatment and highly active antiretroviral therapy on the causespecific risk of mortality among HIV-positive people who inject drugs. Clin Infect Dis 2015;61:1157-65.

29 Reddon H, Milloy M-J, Simo A, et al. Methadone maintenance therapy decreases the rate of antiretroviral therapy discontinuation among HIV-positive illicit drug users. AIDS Behav 2014;18:740-6.

30 Werb D, Milloy M-J, Kerr T, et al. Injection drug use and HIV antiretroviral therapy discontinuation in a Canadian setting. AIDS Behav 2013;17:68-73.

31 Cox J, Graves L, Marks E, et al. Knowledge, attitudes and behaviours associated with the provision of hepatitis $\mathrm{C}$ care by Canadian family physicians. J Viral Hepat 2011;18:e332-40.

32 Kuyper L, Milloy M-J, Marshall BDL, et al. Does initiation of HIV antiretroviral therapy influence patterns of syringe lending among injection drug users? Addict Behav 2011;36:560-3.

33 Young S, Wood E, Milloy M-J, et al. Hepatitis C cascade of care among people who inject drugs in Vancouver, Canada. Subst Abus 2018;39:461-8.

34 Myles A, Mugford GJ, Zhao J, et al. Physicians' attitudes and practice toward treating injection drug users with hepatitis C: results from a national specialist survey in Canada. Can $J$ Gastroenterol 2011;25:135-9.

35 Palepu A, Milloy M-J, Kerr T, et al. Homelessness and adherence to antiretroviral therapy among a cohort of HIV-infected injection drug users. J Urban Health 2011;88:545-55.

36 Kazatchkine C. British Columbia project seeks to improve access to HIV treatment and care among hard-to-reach populations. HIV AIDS Policy Law Rev 2010;14:18-19.

37 Krüsi A, Wood E, Montaner J, et al. Social and structural determinants of HAART access and adherence among injection drug users. Int J Drug Policy 2010;21:4-9.

38 Uhlmann S, Milloy M-J, Kerr T, et al. Methadone maintenance therapy promotes initiation of antiretroviral therapy among injection drug users. Addiction 2010;105:907-13.

39 Doucette KE, Robson V, Shafran S, et al. Improving access to care by allowing self-referral to a hepatitis $\mathrm{C}$ clinic. Can J Gastroenterol 2009;23:421-4

40 Wood E, Hogg RS, Lima VD, et al. Highly active antiretroviral therapy and survival in HIV-infected injection drug users. JAMA 2008;300:550.

41 Cousien A, Leclerc P, Morissette C, et al. The need for treatment scale-up to impact HCV transmission in people who inject drugs in Montréal, Canada: a modelling study. BMC Infect Dis 2017;17:162.

42 Hayashi K, Dong H, Kerr T, et al. Declining mortality rates in HIVinfected people who inject drugs during a Seek-and-Treat initiative in Vancouver, Canada, 1996-2014: a prospective cohort study. $J$ Infect Dis 2017;217:64-8.

43 O'Byrne P, MacPherson P, Roy M, et al. Community-based, nurseled post-exposure prophylaxis: results and implications. Int J STD AIDS 2017;28:505-11.

44 Panagiotoglou D, Krebs E, Min JE, et al. Initiating HCV treatment with direct acting agents in opioid agonist treatment: when to start for people co-infected with HIV? Int J Drug Policy 2017;47:169-76.

45 Socías ME, Ti L, Dong $\mathrm{H}$, et al. High prevalence of willingness to use direct-acting antiviral-based regimens for hepatitis $C$ virus
(HCV) infection among HIV/HCV coinfected people who use drugs. HIV Med 2017;18:647-54.

46 Tran M, Wood E, Kerr T, et al. Increases in CD4 ${ }^{+}$T-cell count at antiretroviral therapy initiation among HIV-positive illicit drug users during a treatment-as-prevention initiative in Canada. Antivir Ther 2017;22:403-11.

47 Lazarus L, Patel S, Shaw A, et al. Uptake of community-based peer administered HIV point-of-care testing: findings from the PROUD study. PLoS One 2016;11:e0166942.

48 Correctional Service Canada. Overdose prevention service, 2019.

49 Kerr T, Mitra S, Kennedy MC, et al. Supervised injection facilities in Canada: past, present, and future. Harm Reduct J 2017;14:28.

50 Small W, Moore D, Shoveller J, et al. Perceptions of risk and safety within injection settings: Injection drug users' reasons for attending a supervised injecting facility in Vancouver, Canada. Health Risk Soc 2012;14:307-24.

51 Pinkerton SD. How many HIV infections are prevented by Vancouver Canada's supervised injection facility? Int J Drug Policy 2011;22:179-83.

52 Reddon H, Wood E, Tyndall M, et al. Use of North America's first medically supervised safer injecting facility among HIV-positive injection drug users. AIDS Educ Prev 2011;23:412-22.

53 Andresen MA, Boyd N. A cost-benefit and cost-effectiveness analysis of Vancouver's supervised injection facility. Int J Drug Policy 2010;21:70-6.

54 Pinkerton SD. Is Vancouver Canada's supervised injection facility cost-saving? Addiction 2010;105:1429-36.

55 Krüsi A, Small W, Wood E, et al. An integrated supervised injecting program within a care facility for HIV-positive individuals: a qualitative evaluation. AIDS Care 2009;21:638-44.

56 Bayoumi AM, Zaric GS. The cost-effectiveness of Vancouver's supervised injection facility. Can Med Assoc J 2008;179:1143-51.

57 Expert Advisory Committee on Supervised Injection Site Research. Vancouver's INSITE Service and Other Supervised Injection Sites: What Has Been Learned from Research? - Final Report of the Expert Advisory Committee on Supervised Injection Site Research [online]. Ottawa, ON, 2008. Available: http://www.hc-sc.gc.ca/ ahcasc/pubs/_site-lieux/insite/index-eng.php

58 Small W, Wood E, Lloyd-Smith E, et al. Accessing care for injection-related infections through a medically supervised injecting facility: a qualitative study. Drug Alcohol Depend 2008;98:159-62.

59 Enns EA, Zaric GS, Strike CJ, et al. Potential cost-effectiveness of supervised injection facilities in Toronto and Ottawa, Canada. Addiction 2016;111:475-89.

60 Jozaghi E, Jackson A. Examining the potential role of a supervised injection facility in Saskatoon, Saskatchewan, to AVERT HIV among people who inject drugs. Int J Health Policy Manag 2015;4:373-9.

61 Shaw A, Lazarus L, Pantalone T, et al. Risk environments facing potential users of a supervised injection site in Ottawa, Canada. Harm Reduct J 2015;12:49.

62 Hadland SE, DeBeck K, Kerr T, et al. Use of a medically supervised injection facility among street youth. $J$ Adolesc Health 2014:55:684-9.

63 Jozaghi E, Reid AA, Andresen MA, et al. A cost-benefit/costeffectiveness analysis of proposed supervised injection facilities in Ottawa, Canada. Subst Abuse Treat Prev Policy 2014;9:31.

$64 \mathrm{Ti}$ L, Kerr T. The impact of harm reduction on HIV and illicit drug use. Harm Reduct J 2014;11:7.

65 Jozaghi E, Andresen MMA. Should North America's first and only supervised injection facility (InSite) be expanded in British Columbia, Canada? Harm Reduct J 2013;10:1.

66 Jozaghi E, Reid AA, Andresen MA. A cost-benefit/costeffectiveness analysis of proposed supervised injection facilities in Montreal, Canada. Subst Abuse Treat Prev Policy 2013;8:25.

67 Grebely J, Drolet M, Nwankwo C, et al. Perceptions and selfreported competency related to testing, management and treatment of hepatitis $\mathrm{C}$ virus infection among physicians prescribing opioid agonist treatment: the C-SCOPE study. Int J Drug Policy 2019;63:29-38.

68 Butt ZA, Shrestha N, Gesink D, et al. Effect of opioid-substitution therapy and mental health counseling on HIV risk among hepatitis C-infected individuals. Clin Epidemiol 2018;10:1127-45.

69 Islam N, Krajden M, Shoveller J. Impact of drug use and opioid substitution therapy on hepatitis $C$ reinfection: the bc hepatitis testers cohort. Hepatology 2016;64:31A-2.

70 Vashishtha D, Mittal ML, Werb D. The North American opioid epidemic: current challenges and a call for treatment as prevention. Harm Reduct J 2017;14:7.

$71 \mathrm{Ti}$ L, Socías ME, Wood E, et al. The impact of methadone maintenance therapy on access to regular physician care 
regarding hepatitis $\mathrm{C}$ among people who inject drugs. PLoS One 2018:13:e0194162.

72 Socías ME, Wood E, McNeil R, et al. Unintended impacts of regulatory changes to British Columbia methadone maintenance program on addiction and HIV-related outcomes: an interrupted time series analysis. Int J Drug Policy 2017;45:1-8.

73 Socías ME, Wood E, Small W, et al. Methadone maintenance therapy and viral suppression among HIV-infected opioid users: the impacts of crack and injection cocaine use. Drug Alcohol Depend 2016;168:211-8.

74 Ahamad K, Hayashi K, Nguyen P, et al. Effect of low-threshold methadone maintenance therapy for people who inject drugs on HIV incidence in Vancouver, bc, Canada: an observational cohort study. Lancet HIV 2015;2:e445-50.

75 Nolan S, Dias Lima V, Fairbairn N, et al. The impact of methadone maintenance therapy on hepatitis $\mathrm{C}$ incidence among illicit drug users. Addiction 2014;109:2053-9.

76 Buxton JA, Kuo ME, Ramji S, et al. Methadone use in relation to hepatitis C virus testing in British Columbia. Can J Public Health 2010;101:491-4.

77 Klimas J, Dong H, Fairbairn N, et al. Eligibility for heroin-assisted treatment (HAT) among people who inject opioids and are living with HIV in a Canadian setting. Addict Sci Clin Pract 2018;13:3.

78 Beaulieu T, Hayashi K, Milloy MJ, et al. Hiv serostatus and having access to a physician for regular hepatitis $C$ virus care among people who inject drugs. J Acquir Immune Defic Syndr 2018;78:93-8.

79 Nouch S, Gallagher L, Erickson M, et al. Factors associated with lost to follow-up after hepatitis $C$ treatment delivered by primary care teams in an inner-city multi-site program, Vancouver, Canada. Int J Drug Policy 2018;59:76-84.

80 Artenie AA, Zang G, Daniel M, et al. Short-term injection drug use changes following hepatitis $\mathrm{C}$ virus $(\mathrm{HCV})$ assessment and treatment among persons who inject drugs with acute HCV infection. Int J Drug Policy 2017;47:239-43.

81 Ti L, Dong H, Kerr T, et al. The effect of engagement in an HIV/AIDS integrated health programme on plasma HIV-1 RNA suppression among HIV-positive people who use illicit drugs: a marginal structural modelling analysis. HIV Med 2017;18:580-6.

82 Fernando S, McNeil R, Closson K, et al. An integrated approach to care attracts people living with HIV who use illicit drugs in an urban centre with a concentrated HIV epidemic. Harm Reduct $J$ 2016;13:31.

83 Wang L, Panagiotoglou D, Min JE, et al. Inability to access health and social services associated with mental health among people who inject drugs in a Canadian setting. Drug Alcohol Depend 2016;168:22-9.

84 Bruneau J, Zang G, Abrahamowicz M, et al. Sustained drug use changes after hepatitis $C$ screening and counseling among recently infected persons who inject drugs: a longitudinal study. Clin Infect Dis 2014;58:755-61.

85 McNeil R, Dilley LB, Guirguis-Younger M, et al. Impact of supervised drug consumption services on access to and engagement with care at a palliative and supportive care facility for people living with HIV/AIDS: a qualitative study. J Int AIDS Soc 2014; 17:18855

86 Newman Al, Beckstead S, Beking D, et al. Treatment of chronic hepatitis $C$ infection among current and former injection drug users within a multidisciplinary treatment model at a community health centre. Can J Gastroenterol 2013;27:217-23.

87 Grebely J, Knight E, Genoway KA, et al. Optimizing assessment and treatment for hepatitis $C$ virus infection in illicit drug users: a novel model incorporating multidisciplinary care and peer support. Eur $J$ Gastroenterol Hepatol 2010;22:270-7.

88 Correctional Service Canada. Prison Needle Exchange [Internet], 2019. Available: http://www.drugsandalcohol.ie/5955/1/Canadian_ HIV Prison needle exchange.pdf

89 Miskovic M, Chan Carusone S, Guta A, et al. Distribution of harm reduction kits in a specialty HIV hospital. Am J Public Health 2018:108:1363-5.

90 van der Meulen E. "It Goes on Everywhere": Injection Drug Use in Canadian Federal Prisons. Subst Use Misuse 2017;52:884-91.

91 Hyshka E, Strathdee S, Wood E, et al. Needle exchange and the HIV epidemic in Vancouver: lessons learned from 15 years of research. Int J Drug Policy 2012;23:261-70.

92 Bruneau J, Daniel M, Abrahamowicz M, et al. Trends in human immunodeficiency virus incidence and risk behavior among injection drug users in Montreal, Canada: a 16-year longitudinal study. Am J Epidemiol 2011;173:1049-58.

93 Ivsins A. Drug use trends in Victoria and Vancouver, and changes in injection drug use after the closure of Victoria's fixed site needle exchange [online]. Vol. 1. Victoria BC, 2010. Available: http:// dspace.library.uvic.ca/handle/1828/4770

94 Gagnon H, Godin G, Alary M, et al. Otis J. A randomized trial to evaluate the efficacy of a Computer-Tailored intervention to promote safer injection practices among drug users. AIDS Behav 2010;14:538-48.

95 Kerr T, Small W, Buchner C, et al. Syringe sharing and HIV incidence among injection drug users and increased access to sterile syringes. Am J Public Heal 2010;100:1449-53.

96 Chu S. Clean switch: the case for prison needle and syringe programs. HIV AIDS Policy Law Rev 2009;14:5-19.

97 Day E, Broder T, Bruneau J, et al. Priorities and recommended actions for how researchers, practitioners, policy makers, and the affected community can work together to improve access to hepatitis C care for people who use drugs. Int J Drug Policy 2019;66:87-93.

98 Skinner S, Cote G, Khan I. Hepatitis C virus infection in Saskatchewan first nations communities: challenges and innovations. Can Commun Dis Rep 2018;44:173-8.

99 Boyd J, Fast D, Hobbins M, et al. Social-structural factors influencing periods of injection cessation among marginalized youth who inject drugs in Vancouver, Canada: an ethno-epidemiological study. Harm Reduct J 2017;14.

100 Rutherford AR, Ramadanovic B, Ahrenberg L. Control of an Hiv epidemic among injection drug users: simulation modeling on complex networks. In: 2016 Winter Simulation Conference (wsc) [online]. New York: leee, 2016: 23-37.

101 Strike C, Hopkins S, Watson TM. Best practice recommendations for Canadian harm reduction programs that provide service to people who use drugs and are at risk for HIV, HCV, and other harms: part 1. Toronto, ON, 2013.

102 Kendall P, Gilbert M, Buxton J. Decreasing HIV infections among people who use drugs by injection in British Columbia: potential explanations and recommendations for further action [onlinet]. Vancouver, BC, 2011.

103 Deering KN, Kerr T, Tyndall MW, et al. A peer-led mobile outreach program and increased utilization of detoxification and residential drug treatment among female sex workers who use drugs in a Canadian setting. Drug Alcohol Depend 2011;113:46-54.10.1016/j. drugalcdep.2010.07.007

104 Hayashi K, Wood E, Wiebe L, et al. An external evaluation of a peer-run outreach-based syringe exchange in Vancouver, Canada. Int J Drug Policy 2010;21:418-21.10.1016/j.drugpo.2010.03.002

105 Hilton BA, Thompson R, Moore-Dempsey L. Evaluation of the AIDS prevention street nurse program: one step at a time. Can J Nurs Res 2009;41:238-58.

106 Cooper CL, Hatashita H, Corsi DJ, et al. Direct-Acting antiviral therapy outcomes in Canadian chronic hepatitis C telemedicine patients. Ann Hepatol 2017;16:874-80.10.5604/01.3001.0010.5277

107 Jongbloed K, Friedman AJ, Pearce ME, et al. The cedar project WelTel mHealth intervention for HIV prevention in young Indigenous people who use illicit drugs: study protocol for a randomized controlled trial. Trials 2016;17:128.10.1186/s13063-016-1250-3

108 Jozaghi E. The role of drug users' advocacy group in changing the dynamics of life in the Downtown Eastside of Vancouver, Canada. J Subst Use 2014;19:213-8.

109 Markwick N, Ti L, Callon C, et al. Willingness to engage in peerdelivered HIV voluntary counselling and testing among people who inject drugs in a Canadian setting. J Epidemiol Community Health 2014;68:675-8.10.1136/jech-2013-203707

110 McNeil R, Small W, Lampkin H, et al. "People knew they could come here to get help": an ethnographic study of assisted injection practices at a peer-run 'unsanctioned' supervised drug consumption room in a Canadian setting. AIDS Behav 2014;18:473-85.10.1007/s10461-013-0540-y

111 Rodger L, Glockler-Lauf SD, Shojaei E, et al. Clinical characteristics and factors associated with mortality in FirstEpisode infective endocarditis among persons who inject drugs. JAMA Network Open 2018;1:e185220.10.1001/ jamanetworkopen.2018.5220

112 Shetty N, Nagpal D, Koivu S, et al. Surgical and medical management of isolated tricuspid valve infective endocarditis in intravenous drug users. J Card Surg 2016;31:83-8.10.1111/ jocs. 12682

113 Bertrand K, Roy Élise, Vaillancourt Éric, et al. Randomized controlled trial of motivational interviewing for reducing injection risk behaviours among people who inject drugs. Addiction 2015;110:832-41

114 Fairbairn N, Milloy M-J, Zhang R, et al. Emergency department utilization among a cohort of HIV-positive injecting drug users in a Canadian setting. J Emerg Med 2012;43:236-43.10.1016/j. jemermed.2011.05.020 
115 Hammett TM, Phan S, Gaggin J, et al. Pharmacies as providers of expanded health services for people who inject drugs: a review of laws, policies, and barriers in six countries. BMC Health Serv Res 2014;14:261.10.1186/1472-6963-14-261

116 Jaworsky D, Phillips P, Cui Z, et al. Trends in discharges from the HIV/AIDS ward at a tertiary Canadian Hospital from 2005 to 2014. AIDS Care 2018;30:1099-106.10.1080/09540121.2018.1434121

117 Aspinall EJ, Nambiar D, Goldberg DJ, et al. Are needle and syringe programmes associated with a reduction in HIV transmission among people who inject drugs: a systematic review and metaanalysis. Int J Epidemiol 2014;43:235-48.10.1093/ije/dyt243
118 Meader N, Li R, Des Jarlais DC, et al. Psychosocial interventions for reducing injection and sexual risk behaviour for preventing HIV in drug users. Cochrane Database Syst Rev 2010;26:CD007192.

119 Phillips KT, Anderson BJ, Herman DS, et al. Risk factors associated with skin and soft tissue infections among hospitalized people who inject drugs. J Addict Med 2017;11:461-7.10.1097/ ADM.0000000000000346

120 Rodger L, Shah M, Shojaei E, et al. Recurrent endocarditis in persons who inject drugs. Open Forum Infect Dis 2019;6:ofz396.

121 Moher D, Liberati A, et al, The PRISMA Group. Preferred reporting items for systematic reviews and meta- analyses: the PRISMA statement. PLoS Med 2009:7. 